\title{
Communication and Social Problems in the Context of Downtown Area Renewal. Case Study of Poznan in Poland
}

\author{
Arch. Bartosz Kazmierczak, PhD \\ Poznan University of Technology, Faculty of Architecture, Poznan, Poland
}

\begin{abstract}
In the following article the attention is paid mainly to public space attractiveness questions. The main idea in a context of aesthetic and functional issues of urban renewal is to enable all the participants to start a dialogue. It is needed so as to identify local community's needs, preferences and aspirations. There is presented a case study of a city of Poznan in the context of a common city centre problems as well as ongoing spatial and social changes.
\end{abstract}

Keywords: urban renewal, public space, traffic calming.

\section{Introduction - Poznan as a study example.}

Poznan is a historical town whose origins dates back to the tenth century. Throughout history, the city's development was dependent on various external factors. Some of them worked on speeding up the urbanization process, others - as the establishment of the Poznan as a fortress, hampered development for centuries. Contemporary Poznan is also subjected to a number of determinants; some have local, other global dimensions. The rapid development of mass media and free flow of information are conducive to the growth of awareness and the formation of civic attitudes. It is a trend that can be observed in many societies - also among the inhabitants of Poznan. District councils, associations and informal groups consociating residents are increasingly involved in matters concerning spatial changes. Location of strategic functions, filling the space with green areas, selection of appropriate equipment or appropriately selected number of parking spaces - those are the problems issued by the municipal activists.

One of the factors that negatively affects the dynamics of spatial transformations leading to the renewal of downtown, is certainly inefficient transportation system. Tailored to the needs of the city of the second half of the twentieth century, where the car was the dominant mean of transportation, now is a generator of many spatial conflicts. The failure of the construction of planned bypasses resulted in the need to broad the streets inside the city and thus fragmentation of urban tissue. Shopping streets connecting the Old Town with the district centers have been cut up and lost its attractiveness due to the lack of continuity of functional relationships and apparent disintegration of space. Of course, not only a bad situation of vehicular communication is responsible for the collapse of Poznan shopping streets. The low level of attractiveness of the downtown public spaces results in increased interest in areas on its periphery and the outflow of capital to these areas. Today, more Poznanians are shopping in shopping centers on suburbs than on the promenades and passages of the Old City. This results in even greater collapse of the valuable fabric of the city and its slow degradation.

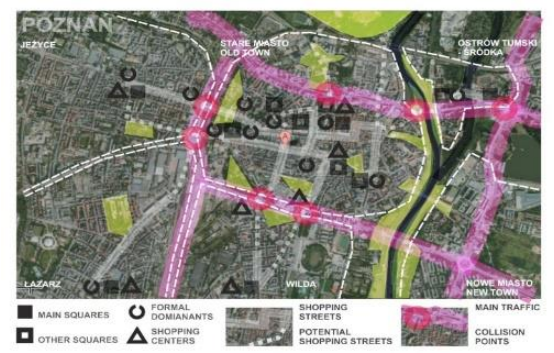

Fig.1. Urban structure of Poznan city centre in a context of main traffic problems. 


\section{Public participation in the process of converting public spaces}

Social and political transformations in Poland and global trends results in the increase of civic awareness also in the field of spatial order. Need to save valuable urban structure is felt by both the inhabitants and the city authorities. In order to improve the state of Poznan public spaces, corrective actions ware taken.

At first, the authorities focused on soft actions, mainly involving the development of spatial awareness of residents and study their preferences as to the desirable forms of land use. Because the term "public participation" was relatively new, it was necessary to bring together different social groups, which have so far been wary to each other. To this end, a series of meetings ware organized, aimed at better understanding of the motivations that guide social groups and an indication of possible fields of consensus on the creation and transformation of urban public spaces. Based on experience gained during the meeting Charter of the Public Space was formulated - a document setting out the basic principles of the creation and use of urban public spaces. In the absence of appropriate legal determinants, the Chart of Public Space has become practically the only document defining the rules of public participation in activities for the recovery of degraded urban areas including the city centers.

In parallel, municipal authorities commissioned the execution of projects for possible changes in relevant spatial development of individual streets. In order to improve the attractiveness of public spaces it was decided to perform studies taking into account such issues as:

- Traffic organization,

- Projects of pavements,

- A small architecture and urban furniture,

- Green areas,

- Advertising and the media.

There was no radical decisions to incorporate in those studies the technical elements of infrastructure, including lighting, water supply etc. The objective of these studies was more to start the debate on the directions of possible transformations than selecting the appropriate solutions that need to be applied. We managed to collect quite a large number of opinions and voices that certainly will help narrow down the search.

However, participation is not only a tool for creation of social design concepts and public consultation of planned investments. The residents readiness for taking action in common spaces manifests itself in increased participation in various kinds of artistic projects that require creativity and an open attitude towards the activities in public space. The creation of fashionable, unique and attractive places require the use of unusual, unexpected solutions. Today's technical capabilities make it possible to design and furnish the space in such a way to provoke users and residents to specific interaction with it. The use of interactive gadgets in the form of smart infrastructural devices, the intentional design of lightning, pavement texture and sound, can make the streets more friendly - mostly for pedestrians and cyclists.

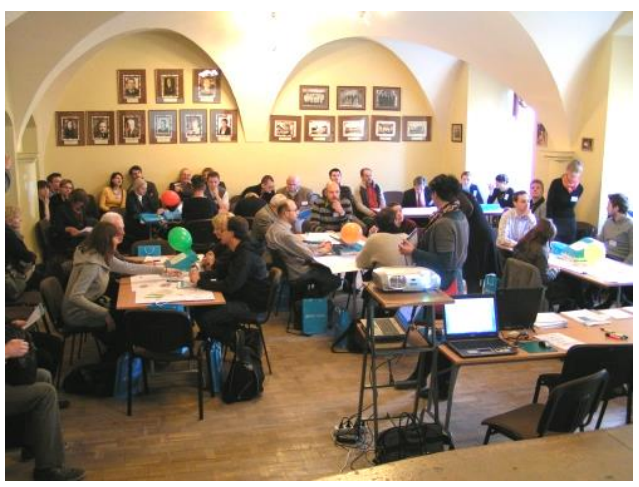

Fig.2. Workshops with public participation is a tool to define needed parking zones. 


\section{The revival of urban public spaces and the problem of vehicular transport domination.}

The increase in the number of cars per capita - observed in Poland at the turn of the XXth century, apply to most Polish cities, including Poznan. According to statistical data in 2008 there were 494 cars per 1000 inhabitants in Poznan. This trend began with the political changes in Poland in the early $90 \mathrm{~s}$. Nuisances caused by automobile traffic are problematic in most city centers. Further expansion of the streets width does not warrant improve in the flow of traffic. The need to protect the downtown urban structures enforces to honour such a width of lanes that stem from the layout of historical quarters. In such circumstances, attempt to comply with the paradigm of dominance of road transport resulted in a drastic reduction in space for pedestrians, which is deadly to small trade and services located along the routes. The balance of the transport system and diversification in the preferred means of transport becomes a priority in this situation. The document accepted November 18, 1999 defines the Urban Transport Policy as compatible with the principles of sustainable development. The detailed resolutions include the restrictions on parking in lanes (Restricted Parking Zones (SOP)), gradual calming of traffic in central districts (TEMPO zone of $30 \mathrm{~km} / \mathrm{h}$ ) and the promotion of public transport and cycling. Restoration of public spaces for the pedestrian use, which was dominated before by traffic, has become one of the directions of activities of the authorities of Poznan.

The first major project was the introduction of restricted parking zones in the City Center and the gradual expansion of the SOP (Restricted Parking Zones) in downtown districts. The introduction of the zone in a given area is always associated with conducting public consultations with district councils. The author had the opportunity to make urban spatial development plan for downtown district of Wilda. Project covered area adjacent to the Old Town and running up to the Wildecki Market- the main square of the district. The objectives of the project was traffic calming within a main street connecting Market Wildecki Market with the Old Town, regulate and organize the parking spaces in such a way as to minimize their negative impact on the perception of space by pedestrians.

The project introduced solutions untapped in Poland, the so called sharing of the communication space through various forms of transport and pedestrians, such as junction with the lock for passantes, raising the crossings to the sidewalk levels, as well as already known in Poznan traffic calming elements such as road chicanes used for greenery or small architecture. The purpose of these operations was to adjust the speed of vehicles to $30 \mathrm{~km} / \mathrm{h}$.

Another example of a city program aimed at reducing the dominance of cars in the city center, thus giving space to pedestrians and cyclists, is the TEMPO 30 ZONE, which means the designation of areas with limited maximum speed to $30 \mathrm{~km} / \mathrm{h}$ and traffic reorganization in such a way as to prevent transit traffic through the Old Town. Municipal Road Authority in Poznan proceeded to draw up a concept of reorganization of traffic and the creation of new spaces for the pedestrians on Św. Marcin street. In the past it used to be the main shopping street, currently it is badly organized, overgrown with functions incongruent with the rank of the place. Original project commissioned by the Municipal Road Authority did not seek specific engineering solutions, but provoked a discussion not only of experts and activists but also ordinary users.

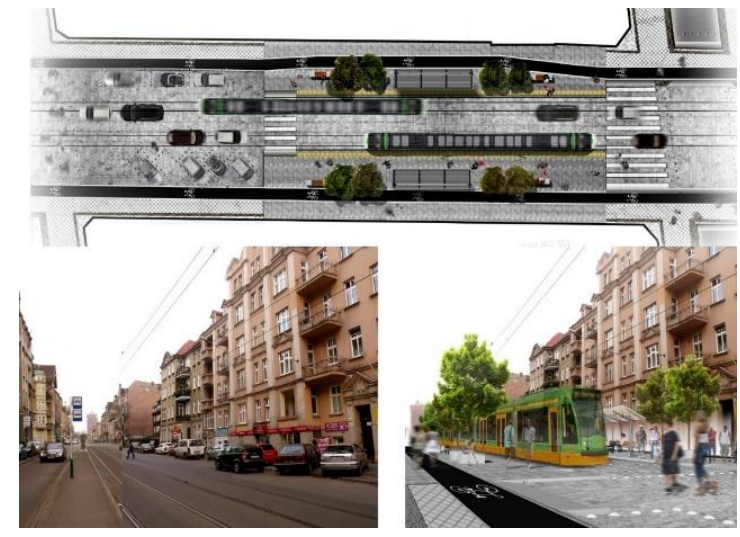

Fig.3. Concept of public space renewal with new organization of traffic and improvement of urban inerior elements. 


\section{Summary}

Strengthening of the local awareness and building urban strategies based on the unique characteristics of individual districts may be the beginning of a long process of renewal of the city center in both the spatial and socio-economic layer. One of the most important elements of urban structure, which role is to create a unique identity, is a system of public spaces of a downtown. This system is a space of increased interaction and social contact as it is the carrier of cultural heritage values. Composed of markets, squares, streets and parks, it reflects the level of social culture and defines the framework for social life. All design decisions and actions redefining these spaces are not only important spatial and economical terms, but also social. The public space has different social functions because of their "equipment" and purpose. Downtown must therefore be subject to continuous evolution and spatial changes made in terms of today's economic and social needs.

Public debate on the future of Poznan public spaces, as well as active participation of the municipalities and expert groups, points to greater openness of the authorities to the needs and demands. On the other hand, the positive trend is occurring for several years in revival in the creative sector, groups of local activists, creative environments, nonprofits and others for whom the matter of the balance in the city and development of culture has become a common idea. Public participation in shaping a new and better image of the degraded areas of the city coincides with the role of the architect - urban planner and includes not only involvement in creation of programs, projects or other documents but also active participation in the life of the city.

\section{References}

[1] Kaźmierczak B. (2014) "When formal becomes informal", Rethinking the Urban, DAKAM, ISBN: 978-605-512024-5, Istambul, 2013

[2] Kaźmierczak B., Social and cultural aspects of a city public space transformation. Case study of Poznan, Poland, MCSER Publishing, Mediterranean Journal of Social Sciences, Vol.5, No.19, August 2014, Rome-Italy

[3] Kaźmierczak B., Touristic infrastructure development in the context of increasing a town space attractiveness, New Perspectives On Economics And Business Studies, EUSER - European Center For Science Education And Research, Rome, Italy, 2015

[4] Kaźmierczak B., Pazder D., Participation in public space renewal. Case study of Poznan - large city in Poland, European Journal of Social Sciences Education and Research, vol. $6 \mathrm{nr} 2,2016$ 